\title{
PRODUÇÃO ACADÊMICA E EDUCACIONAL DE UM DISCENTE DE MESTRADO EM EPT DO IFAP MACAPÁ, AMAPÁ, AMAZÔNIA, BRASIL
}

\section{ARTIGO ORIGINAL}

VIANA, Valderi Nascimento ${ }^{1}$, FECURY, Amanda Alves², OLIVEIRA, Euzébio de ${ }^{3}$, DENDASCK, Carla Viana ${ }^{4}$, DIAS, Claudio Alberto Gellis de Mattos ${ }^{5}$

VIANA, Valderi Nascimento. Et al. Produção Acadêmica E Educacional De Um Discente De Mestrado Em EPT Do IFAP Macapá, Amapá, Amazônia, Brasil. Revista Científica Multidisciplinar Núcleo do Conhecimento. Ano 06, Ed. 06, Vol. 08, pp. 186-200. Junho de 2021. ISSN: 2448-0959, Link de acesso: https://www.nucleodoconhecimento.com.br/educacao/discente-de-mestrado, DOI: 10.32749/nucleodoconhecimento.com.br/educacao/discente-de-mestrado

\section{RESUMO}

A produção científica dentro de cursos de graduação e pós-graduação tem sua importância para a construção de uma nova forma de pensar do discente. O Mestrado Profissional em Educação Profissional em Rede Nacional (ProfEPT) une o conteúdo disciplinar, saberes pedagógicos, e a produção acadêmica final e os vincula a situações reais da prática educacional, podendo o trabalho final ser apresentado de várias formas (artigos, livros, produtos educacionais). A produção acadêmica, tanto

\footnotetext{
${ }^{1}$ Educador Físico, Especialista em Fisiologia do Exercício e Nutrição Esportiva (FAMA), Discente do Programa de Pós-Graduação em Educação Profissional e Tecnológica (PROFEPT IFAP).

${ }^{2}$ Biomédica, Doutora em Doenças Tropicais, Professora e pesquisadora do Curso de Medicina do Campus Macapá, Universidade Federal do Amapá (UNIFAP).

${ }^{3}$ Biólogo, Doutor em Doenças Tropicais, Professor e pesquisador do Curso de Educação Física da Universidade Federal do Pará (UFPA).

${ }^{4}$ Teóloga, Doutora em Psicanálise Clínica. Atua há 15 anos com Metodologia Científica ( Método de Pesquisa) na Orientação de Produção Científica de Mestrandos e Doutorandos. Especialista em Pesquisas de Mercado e Pesquisas voltadas a área da Saúde. Doutoranda em Comunicação e Semiótica (PUC SP).

${ }^{5}$ Biólogo, Doutor em Teoria e Pesquisa do Comportamento, Professor e pesquisador do Curso de Licenciatura em Química do Instituto de Ensino Básico, Técnico e Tecnológico do Amapá (IFAP) e do Programa de Pós Graduação em Educação Profissional e Tecnológica (PROFEPT IFAP).
} 
do orientador como do orientando, além da importância ligada a divulgação científica, tem peso na avaliação do programa e, também, na sua manutenção. O objetivo deste trabalho é mostrar quantitativamente a produção acadêmica e educacional de um discente de mestrado em Educação Profissional e Tecnológica (EPT) do Instituto de Educação, Ciência e Tecnologia (IFAP) de Macapá, Amapá, Amazônia, Brasil. Durante o mestrado a produção científica em várias formas se mostrou necessária durante o processo de formação. Unindo a teoria com a prática da escrita, facilitou a produção da dissertação que deve ser apresentada ao final do curso. Através do processo de organização, planejamento das ideias resultou em um novo pensamento estruturado de acordo com as normas da academia, mas que não se limita a esse espaço e normas. A produção no decorrer do mestrado procura contribuir tanto quantitativamente quanto qualitativamente para a produção científica da região norte, impactando de forma positiva nela e no programa de mestrado. Além da importância na contribuição da criação e divulgação científica, as produções tendem a impactar positivamente na avaliação e na manutenção do programa PROFEPT-IFAP, realizadas pela CAPES.

Palavras-chave: EPT, Divulgação, Produção Científica, PRORFEPT.

\section{INTRODUÇÃO}

Unindo instrumentos teóricos e metodológicos oportuniza a realização de novos projetos, o aluno deixa de ser apenas um repetidor e começa a produzir conhecimento, contribuindo com uma temática ou área específica. Através da construção do próprio pensamento produzem novas atitudes e comportamentos, ou seja, expõe uma ideia plausível e estruturada, apresentam juízos de valor e senso crítico com uma argumentação válida e lógica (Maia, 2008).

O Mestrado Profissional em Educação Profissional em Rede Nacional (ProfEPT) surge como uma oportunidade de uma formação específica sobre a Educação Profissional e Tecnológica tanto para os funcionários do Institutos Federais quanto para a população externa, tendo a produção de conhecimento através de produtos 
educacionais e de realizações de pesquisas que relacionam ao mundo do trabalho. Nessa modalidade, o objetivo é a união do conteúdo disciplinar e dos saberes pedagógicos, a produção acadêmica final deve estar vinculada a situações reais da prática educacional, podendo o trabalho final ser apresentado de várias formas (Machado e Urbanetz, 2019; Urbanetz et al., 2020).

Para a produção e publicação de conhecimento científico, a orientação tem um papel fundamental. O orientador tendo uma ampla experiência em publicação, torna-se um mentor para o seu orientando, impactando de forma positiva a produtividade, sendo responsável pelo progresso de aprendizagem e sucesso no futuro do discente. Ou seja, toda a experiência adquirida durante o processo de formação tem um impacto positivo na vida acadêmica do aluno, as competências e habilidades para publicação são aprendidas durante a formação (Falaster et al., 2017).

De acordo com a ficha de avaliação para programas acadêmicos e profissionais (Área 46: Ensino) da Coordenação de Aperfeiçoamento de Pessoal de Nível Superior (CAPES):

[...] será avaliada a capacidade mínima de produção relevante dos DP, podendo envolver discentes e egressos. Também, será avaliada a aderência e alinhamento da produção indicada pelos DP do PPG (quatro produções) com sua área de concentração e linhas de pesquisa, refletindo a coerência da produção com os objetivos e com a identidade do Programa. [...] Para isso, o PPG indicará até cinco produções bibliográficas e até cinco PTT publicadas no quadriênio envolvendo discentes e egressos. [...] a relevância da produção indicada em relação ao Impacto e caráter inovador da produção intelectual, à abrangência local, regional, nacional ou internacional, e ao atendimento a demandas sociais. (Capes, 2020).

A produção acadêmica, tanto do orientador como do orientando, além da importância ligada a divulgação científica, tem peso na avaliação do programa de pós-graduação stricto sensu e, também, na sua manutenção. 


\section{OBJETIVO}

Demonstrar quantitativamente a produção acadêmica e educacional de um discente de mestrado em Educação Profissional e Tecnológica (EPT) do Instituto de Educação, Ciência e Tecnologia (IFAP) de Macapá, Amapá, Amazônia, Brasil.

\section{METODOLOGIA}

Neste artigo, expõe-se a produção intelectual desenvolvida durante o ProfEPT IFAP. Essas produções que podem ser classificadas como produção bibliográfica (artigo em periódico, livro) e produção Técnica (aplicativo - APP, site)

As pesquisas quantitativas para obter os dados sobre o aplicativo e o site utilizaram o período entre 12 de abril de 2021 a 14 de junho de 2021. Os dados sobre o aplicativo foram retirados do Play Console (Playconsole, 2021) e sobre o site do Google Analytics (Googleanalytics, 2021).

Para os livros e artigos científicos foi utilizada a data original de publicação até 14 de junho de 2021. Os dados sobre eles foram retirados dos dados on line (livros e artigos publicados Revista Multidisciplinar Núcleo do Conhecimento) (Rmnc, 2021) e também por consulta direta à revista (artigo publicado no Research, Society and Development journal) (Rsd, 2021).

\section{RESULTADOS}

\section{APLICATIVO EFE (EDUFISEPT)}

A figura 1 apresenta a porcentagem de instalações do aplicativo EFE pela origem do tráfego de informações, entre 12 de abril e 14 de junho de 2021. Os dados mostram que 21.67\% (13 usuários) chegaram ao app através de pesquisa dentro da loja do Google play e $78.30 \%$ (47 usuários) através de link de terceiros. 
Figura 1 - Mostra a porcentagem de instalações do aplicativo EFE pela origem do tráfego de informações, entre 12 de abril e 14 de junho de 2021.

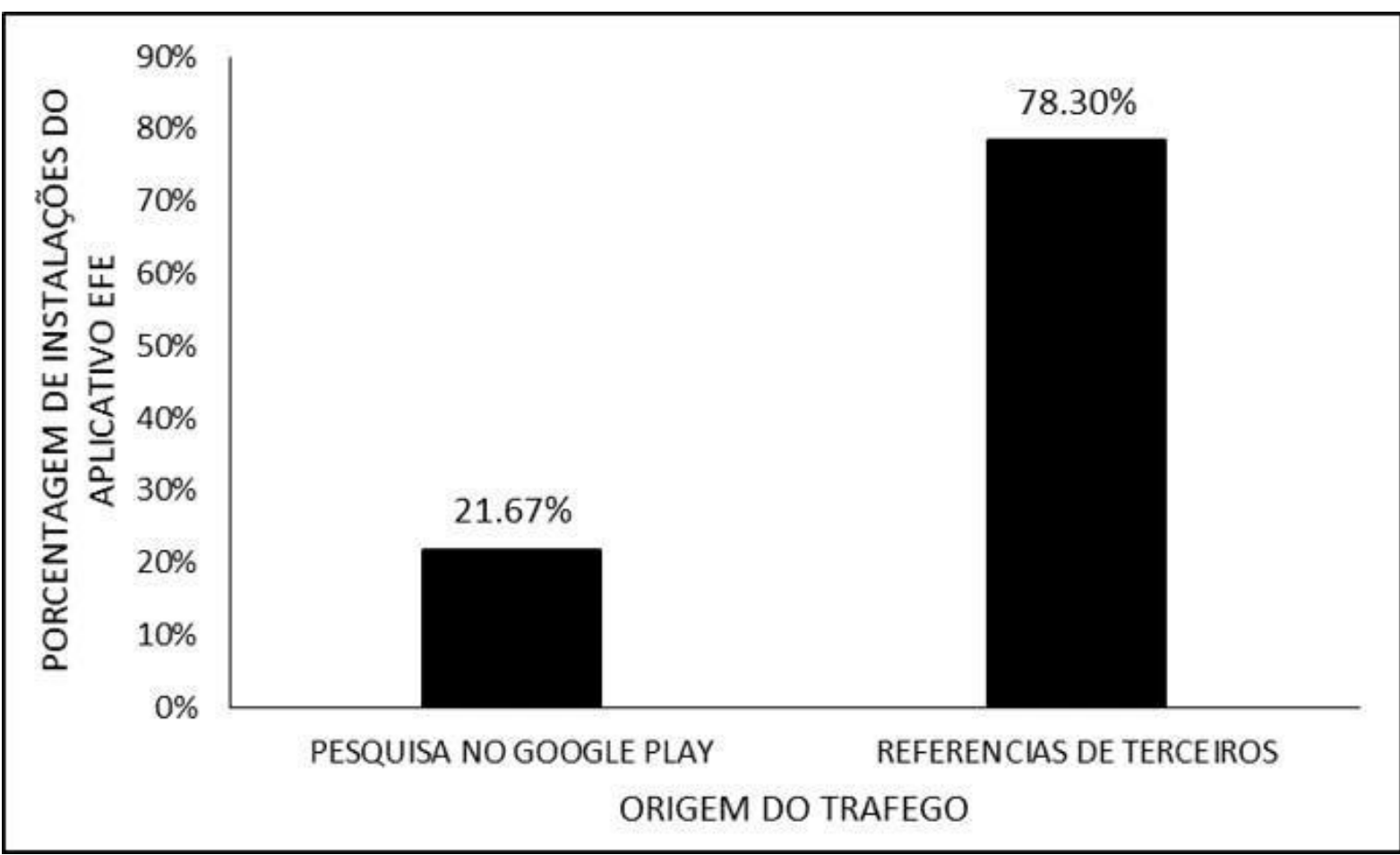

Fonte: Adaptado de Playconsole (2021)

Quanto a análise da porcentagem de instalações do aplicativo EFE pelo país do usuário, entre 12 de abril e 14 de junho de 2021, houve registro de downloads em dois países, sendo $98.33 \%$ (59 downloads) do Brasil e 1.67\% de Portugal (01 download) (Figura 2). 
Figura 2 - Mostra a porcentagem de instalações do aplicativo EFE pelo país do usuário, entre 12 de abril e 14 de junho de 2021.

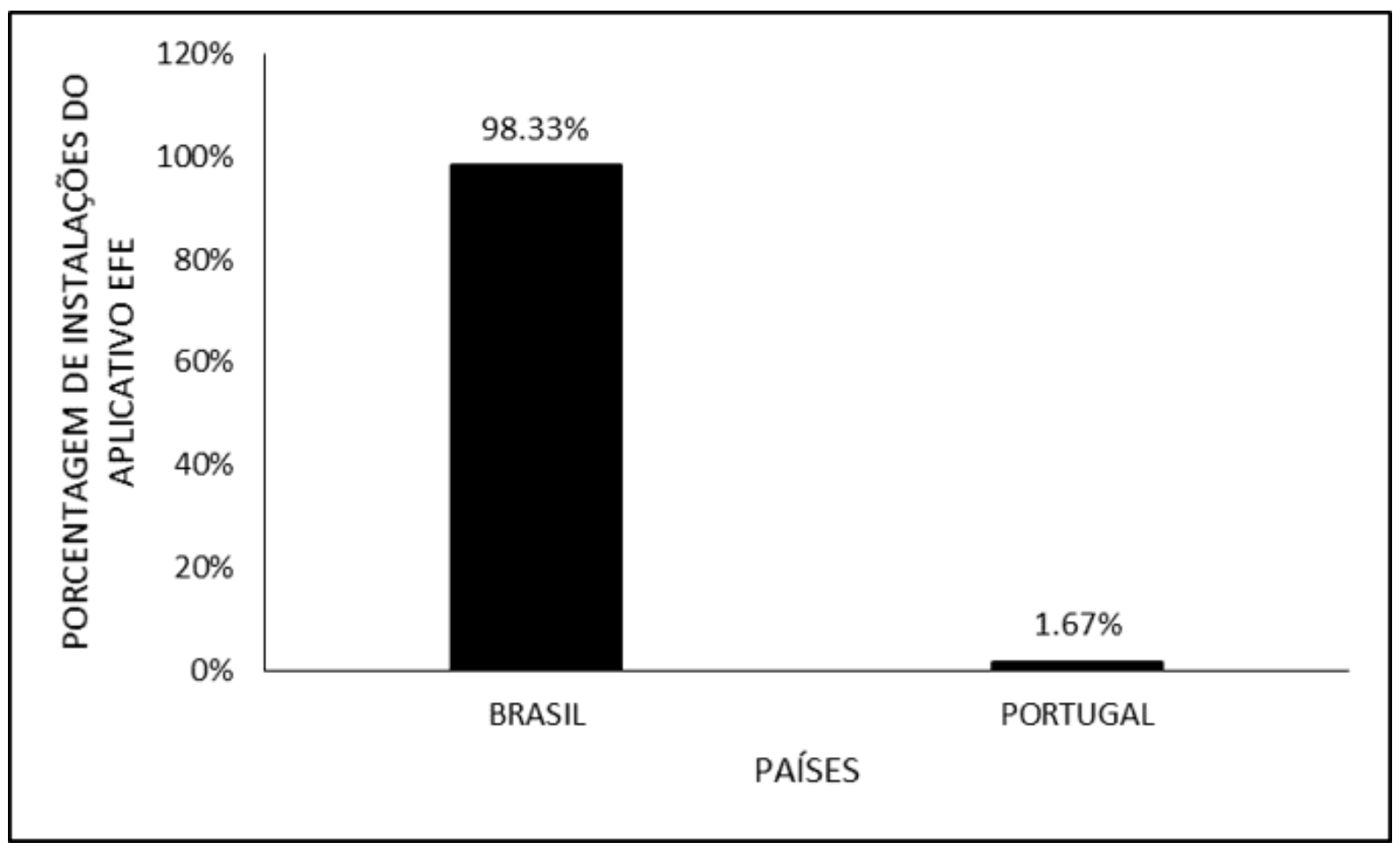

Fonte: Adaptado de Playconsole (2021)

A porcentagem de instalações do aplicativo EFE pela visita ao app e instalação, entre 12 de abril e 14 de junho de 2021, pode ser vista na figura 3. De 100\% dos visitantes da página na loja (82 pessoas), 73.17\% (60 pessoas) realizaram o download do aplicativo em seu dispositivo móvel (Figura 3). 
Figura 3 - Mostra a porcentagem de instalações do aplicativo EFE pela visita ao app e instalação, entre 12 de abril e 14 de junho de 2021.

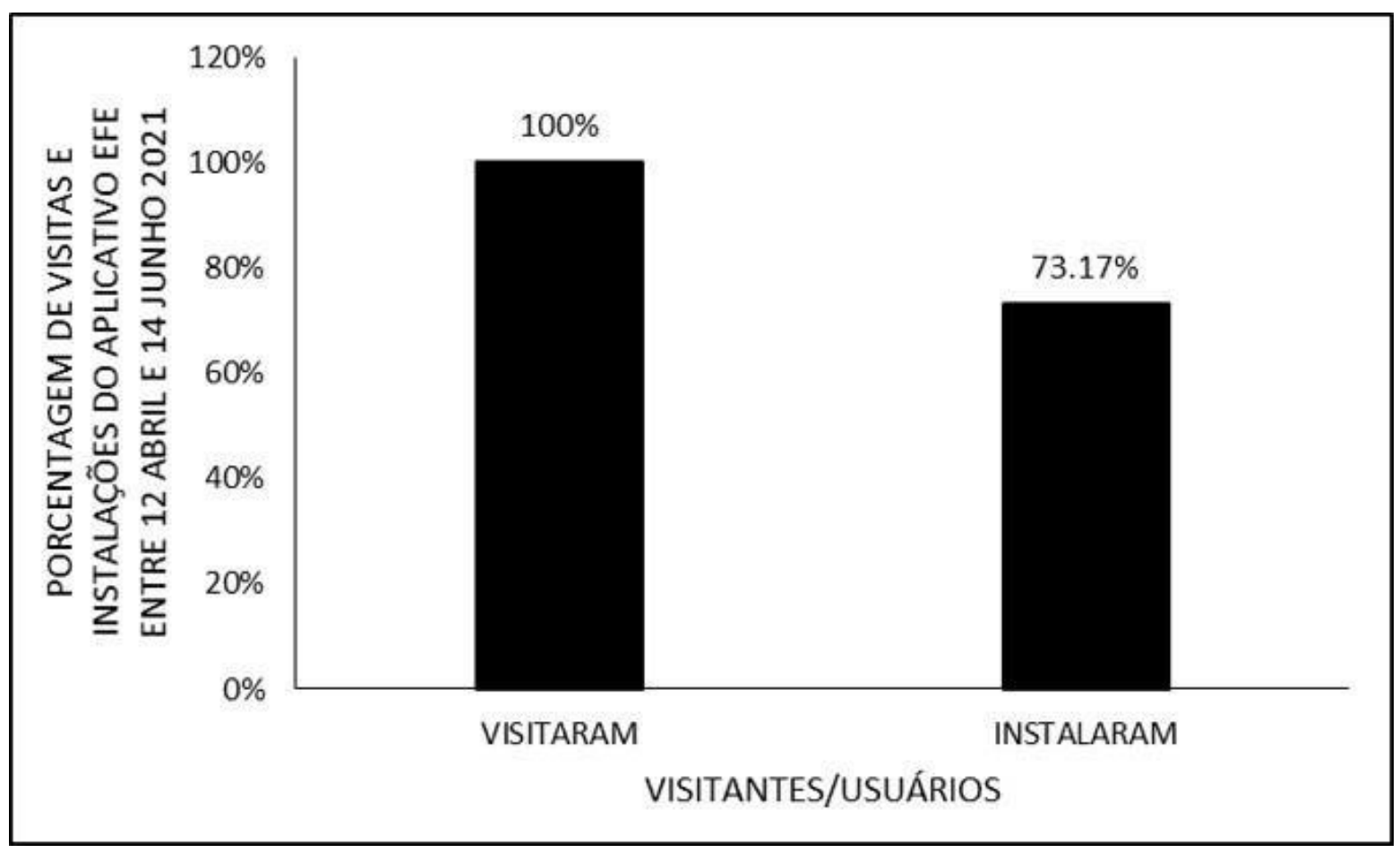

Fonte: Adaptado de Playconsole (2021)

A figura 4 mostra a porcentagem de instalações do aplicativo EFE pelos tipos de usuários, entre 12 de abril e 14 de junho de 2021. Do total (60 usuários), 93.33\% (56 pessoas) são novos usuários e 6.67\% (04 pessoas) são usuários recorrentes dentro do aplicativo, ou seja, acessaram várias vezes o APP. 
Figura 4 - Mostra a porcentagem de instalações do aplicativo EFE pelos tipos de usuários, entre 12 de abril e 14 de junho de 2021.

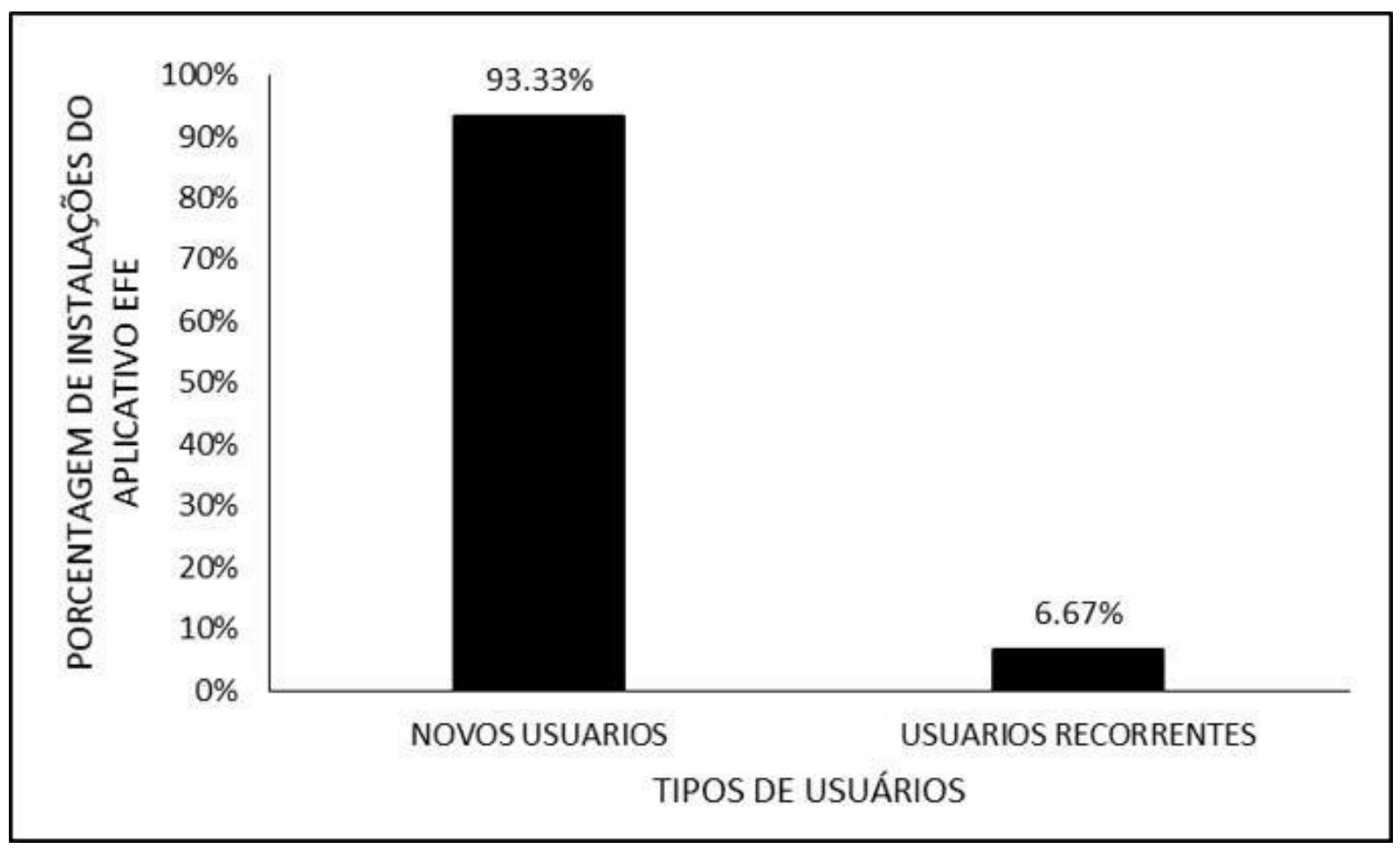

Fonte: Adaptado de Playconsole (2021)

\section{SITE}

Em relação a porcentagem de acessos ao site EduFisEPT por páginas internas do site, entre 12 de abril e 14 de junho de 2021, a página com mais acessos entre os 1399 usuários (100\%) é a de Práticas pedagógicas com 30.38\% (425 pessoas). Em seguida a página de Esportes com 17.23\% (241 pessoas acessando), Autores com 13.37\% (187 pessoas), Colabore com 13.22\% (185 pessoas), Jogos e brincadeiras com $7.79 \%$ (109 pessoas acessando), Danças 5.65\% (79 pessoas), Saúde com $5.00 \%$ (70 pessoas), Lazer com 4.43\% (62 pessoas) e Lutas com $2.91 \%$ (41pessoas) (Figura 5). 
Figura 5 - Mostra a porcentagem de acessos ao site EduFisEPT por páginas internas, entre 12 de abril e 14 de junho de 2021.

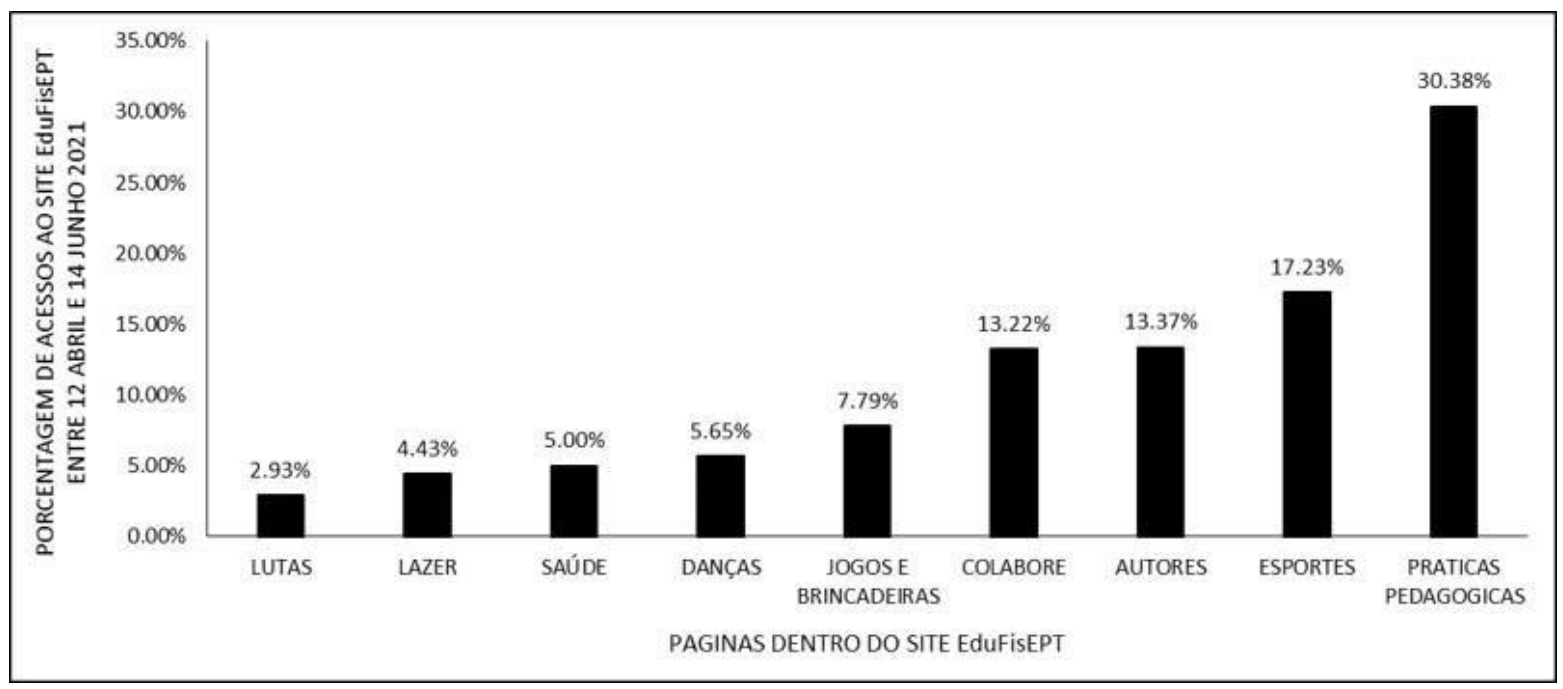

Fonte: Adaptado de GoogleAnalytics (2021)

A porcentagem de acessos ao site EduFisEPT por países, entre 12 de abril e 14 de junho de 2021, traz o Brasil com 93.92\% (1314 pessoas) acessos, seguido de Portugal com 2.64\% (37 pessoas), Estados Unidos com 1.50\% (21 pessoas), Moçambique $1.07 \%$ (15 pessoas), $1.07 \%$, e Irlanda com $0.86 \%$ (12 pessoas) (Figura 6). 
Figura 6 - Mostra a porcentagem de acessos ao site EduFisEPT por países, entre 12 de abril e 14 de junho de 2021.

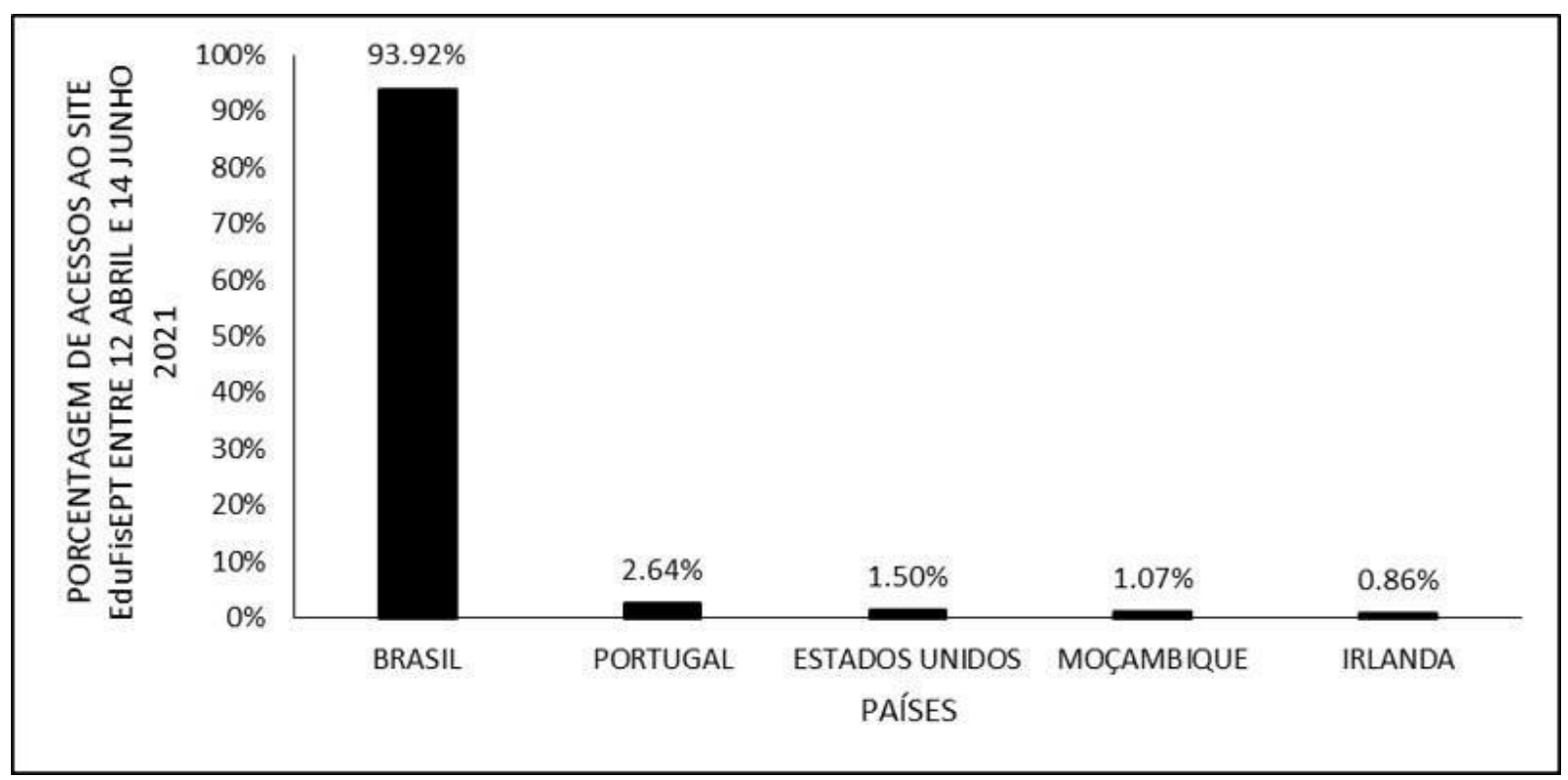

Fonte: Adaptado de GoogleAnalytics (2021)

\section{LIVROS}

A figura 7 mostra a capa do livro publicado em língua portuguesa (BR) em 30 de setembro de 2020. Desde a sua publicação, o livro acumula um total de 715 visualizações. 
Figura 7 - Mostra a capa do livro publicado em língua portuguesa (BR) em 30 de setembro de 2020.

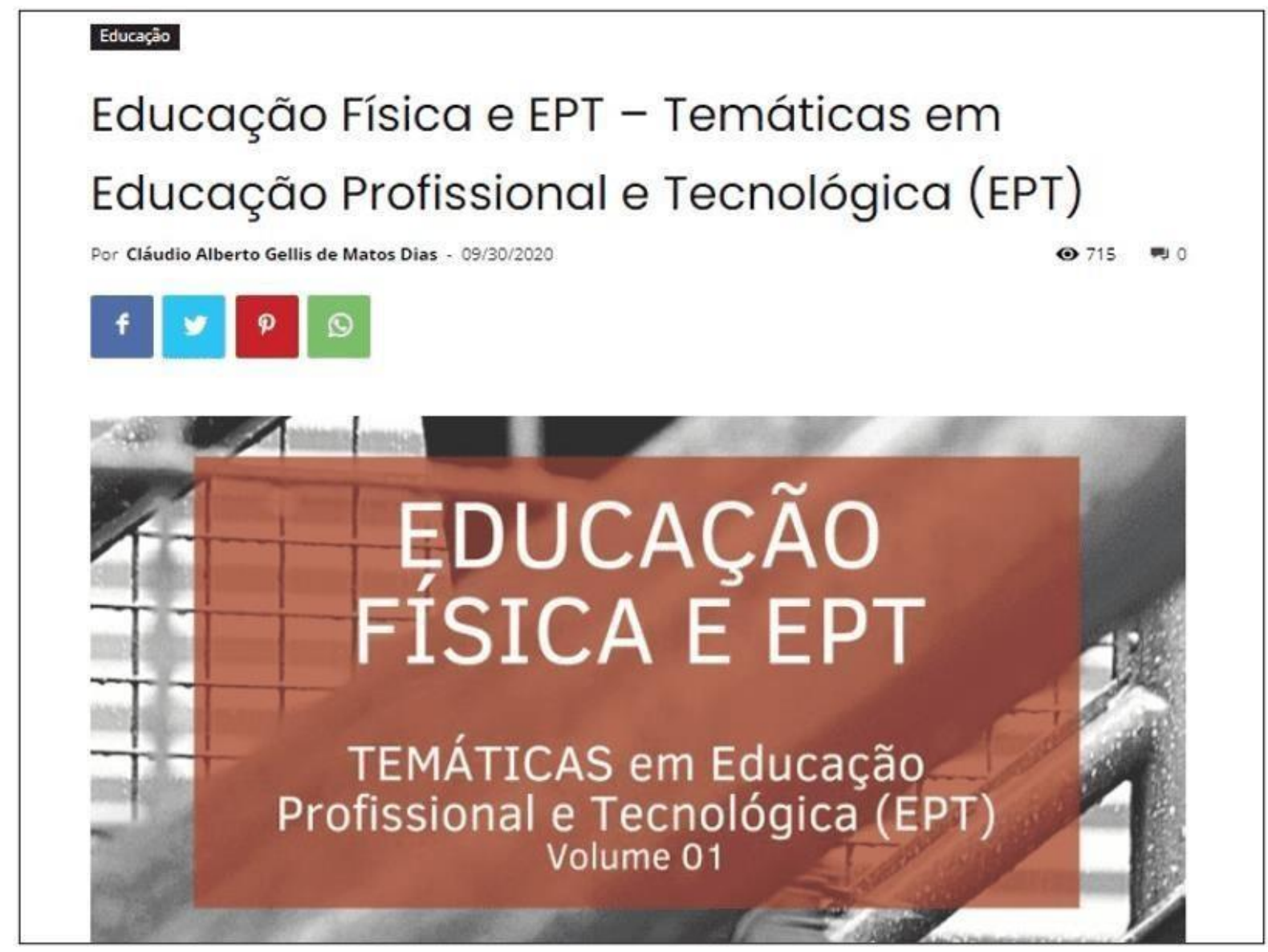

Fonte: Adaptado de Viana e Dias (2020).

O livro publicado em língua inglesa (versão do livro em português) em 10 de dezembro de 2020 acumula 248 visualizações desde então (Figura 8). 
Figura 8 - Mostra a capa do livro publicado em língua inglesa em 10 de dezembro de 2020.

Education

Physical Education and PTE - Topics in

Professional and Technological Education

(PTE)

Por Cláudio Alberto Gellis de Matos Dias - 12/10/2020 O 248 0
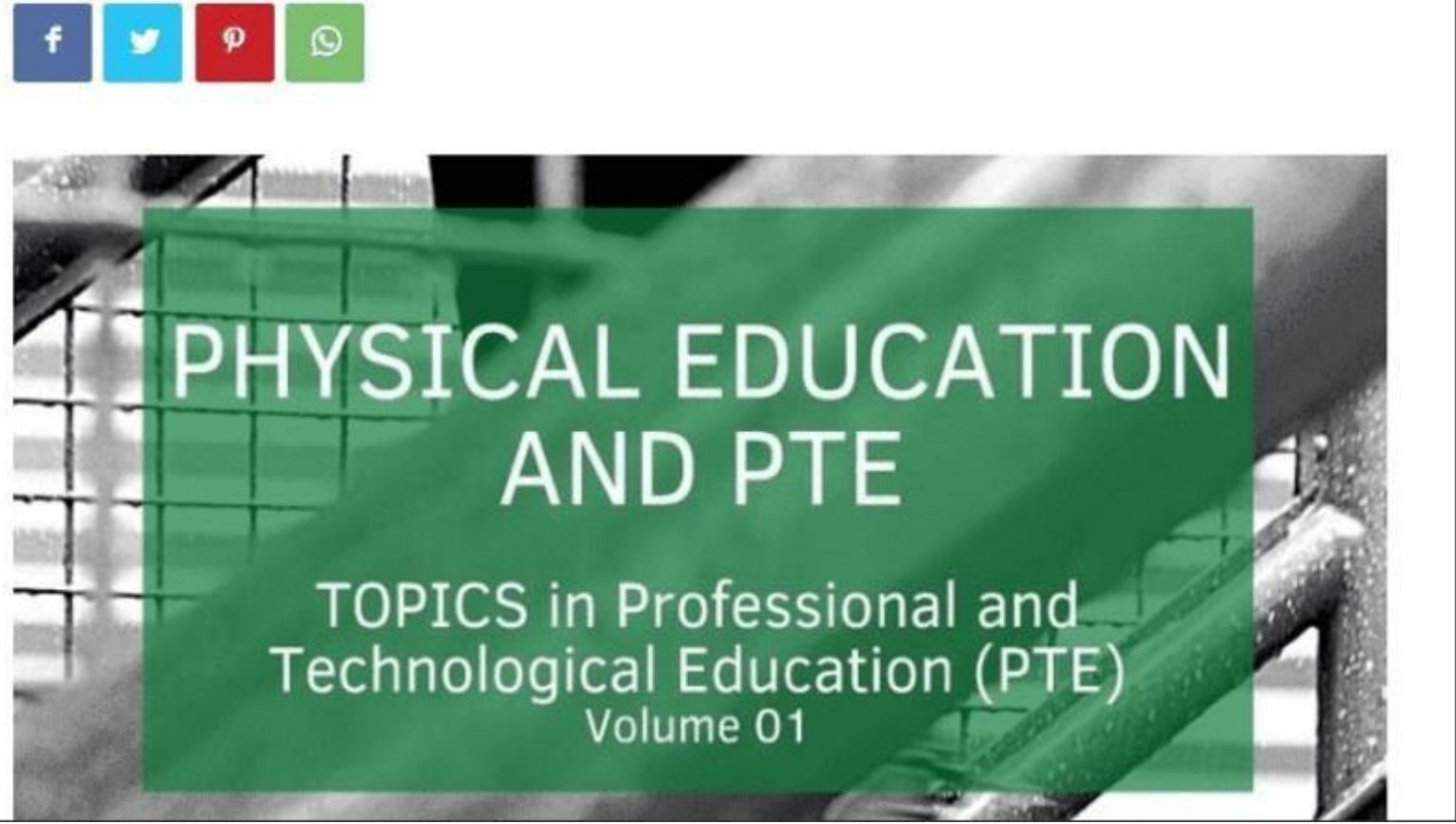

Fonte: Adaptado de Viana e Dias (2020b).

\section{ARTIGOS PUBLICADOS EM REVISTAS INDEXADAS}

O artigo publicado na revista Research, Society and Development (Qualis 2013-2016 B2 e Qualis referência A3) em 02 de julho de 2020 teve, segundo informação dos editores, 91 visualizações (Figura 9). 
Figura 9 - Mostra a capa do artigo publicado na revista Research, Society and Development em 02 de julho de 2020.

\begin{tabular}{|} 
Research, Society and Development, v. 9, n. 8, e239985704. 2020 \\
(CC BY 4.0) | ISSN 2525-3409| DOI: http://dx.doi.org/10.33448/1sd-v9i8.5704 \\
Quadras de esportes em condições de uso adequado no Brasil: \\
influência no ensino-aprendizagem nas aulas de Educação Física (2015) \\
Sports courts in conditions of proper use in Brazil: influence on teaching-learning in \\
Physical Education classes (2015) \\
Canchas deportivas en condiciones de uso adecuado en Brasil: \\
influencia en la enseñanza-aprendizaje en las clases de Educación Física (2015) \\
Recebido: 16/06/2020 | Revisado: 18/06/2020 | Aceito: 22/06/2020 | Publicado: 02/07/2020 \\
ORCD: https://orcid.org/0000-0002-0885-5834 \\
Instituto Federal do Amapá, Brasil \\
E-mail: wallderinascimento@gmail.com
\end{tabular}

A figura 10 mostra a capa do manual sobre o aplicativo EFE publicado na Revista Multidisciplinar Núcleo do Conhecimento (Qualis referência B3) em 14 de abril de 2021. A publicação em português teve 244 visualizações. 
Figura 10 - Mostra a capa do manual sobre o aplicativo EFE publicado na Revista Multidisciplinar Núcleo do Conhecimento em 14 de abril de 2021.

\section{Educaçâo Fisica}

MANUAL DE PRATICAS EM EDUCAÇÃO FISICA NA EDUCAÇÃO PROFISSIONAL E TECNOLÓGICA UTILIZANDO O APLICATIVO GRATUITO EFE - EPTFIS

Por Carla Dendasck - RC: 82194 - 14/04/2021

○ $244 \Rightarrow 0$

DOI: $10.32749 /$ nucleodoconhecimento.com.br/educacao-fisica/manual-de-praticas

\section{ARTIGO ORIGINAL}

VIANA, Valderi Nascimento [1], FECURY, Amanda Alves [2], OLIVEIRA, Euzébio de [3], DENDASCK, Carla Viana [4], DIAS, Claudio Alberto Gellis de Mattos [5]

Fonte: Adaptado de Viana et al. (2021)

O manual foi publicado em mais seis línguas, além da língua portuguesa. A tabela 1 mostra o número de acessos (e a URL) ao manual sobre o aplicativo EFE publicado na Revista Multidisciplinar Núcleo do Conhecimento até 14 de junho de 2021, por idioma. No total, desde a publicação até a data de 14 de junho de 2021 foram 374 visualizações. 
Tabela 1 - Mostra o número de acessos (e a URL) ao manual sobre o aplicativo EFE publicado na Revista Multidisciplinar Núcleo do Conhecimento até 14 de junho de 2021, por idioma.

\begin{tabular}{|c|c|c|}
\hline IDIOMA & \begin{tabular}{|} 
NÚMERO \\
DE \\
ACESSOS
\end{tabular} & LINK DE ACESSO \\
\hline PORTUGUES & 244 & $\begin{array}{c}\text { https://www.nucleodoconhecimento.com.br/e } \\
\text { ducacao-fisica/manual-de-praticas }\end{array}$ \\
\hline INGLES & 20 & $\begin{array}{c}\text { https://www.nucleodoconhecimento.com.br/e } \\
\text { ducation-physics-en/manual-of-practices }\end{array}$ \\
\hline ESPANHOL & 24 & $\begin{array}{l}\text { https://www.nucleodoconhecimento.com.br/e } \\
\text { ducacion-fisica-es/manual-de-practicas }\end{array}$ \\
\hline FRANCÊS & 23 & $\begin{array}{l}\text { https://www.nucleodoconhecimento.com.br/e } \\
\text { ducation-physics-fr/manuel-de-pratiques }\end{array}$ \\
\hline ITALIANO & 26 & $\begin{array}{c}\text { https://www.nucleodocon hecimento.com.br/e } \\
\text { ducazione-fisica-it/manuale-di-pratiche }\end{array}$ \\
\hline ALEMÃO & 21 & $\begin{array}{c}\text { https://www.nucleodoconhecimento.com.br/b } \\
\text { ildung-physik-de/handbuch-der-praktiken }\end{array}$ \\
\hline RUSSO & 16 & $\begin{array}{l}\text { https://www.nucleodocon hecimento.com.br/o } \\
\text { бразование-физика-ru/пособие-по-практике, }\end{array}$ \\
\hline TOTAL & 374 & \\
\hline
\end{tabular}

Fonte: Adaptado de Viana et al. (2021), Viana et al. (2021b), Viana et al. (2021c), Viana et al. (2021d), Viana et al. (2021e), Viana et al. (2021f), Viana et al. (2021g).

\section{DISCUSSÃO}

Dentro do meio científico, toda a teoria e metodologia busca aproximar o aluno do conhecimento produzido pela ciência. Dentro do processo de formação o contato com a escrita de artigos, construção de sites e do aplicativo, a construção da pesquisa, análise de dados e divulgação, mostrou-se de grande importância. Em cada produção há uma realidade sendo pesquisada, e essa estabelece uma ligação com situações e contextos socioculturais. A contextualização do conhecimento é uma ferramenta para 
uma aprendizagem significativa. Oportuniza-se vivência, experiência de novos ou ressignificação de conhecimentos, é desenvolver a habilidade de análise, hipóteses, senso crítico dentro de uma estrutura atual, uma vez que ocorre a interação com fatos e fenômenos do cotidiano (Yamaguchi e Furtado, 2019).

Todos os materiais publicados, fisicamente ou on-line, servem como meio de divulgação científica. No caso do aplicativo todos os conteúdos abordados estão baseados em saberes científicos, por um acesso fácil e simples. O professor adquire novos saberes podendo colocar em prática dentro da escola em tempo real. De acordo com Rossi (2019)

Falta trazer a ciência dos artigos e dos congressos para mais próximo da vida de brasileiros que tanto precisam de quase tudo no que diz respeito à saúde, qualidade de vida, sustentabilidade, mobilidade, usos de tecnologia e cidadania.

Dessa forma, tanto no plano teórico (artigos, livros, site) e aplicação do app servem como um estímulo à vivência científica, é pensar em ciência articulada com a realidade, de acesso e linguagem acessível para qualquer um que procure conhecimento. A divulgação está além de levar um saber sistematizado, também serve para encantar, motivar e estimular o outro. (Rossi, 2019).

Na educação física, ainda é muito forte a visão de uma prática apurada na técnica pela técnica ou no rendimento esportivo. O rendimento e a técnica devem ser considerados pelo professor, mas não vistas como prioridades e que devem estar dentro de um padrão de excelência sem respeitar a individualidade do aluno. Dentro de uma perspectiva de formação global, as aulas de educação física devem trabalhar o seu objeto de estudo em uma ampla dimensão, uma vez que os alunos estão inseridos dentro de uma sociedade que tem uma cultura e que produz significados, bem como revela contradições de comportamentos, atitudes que devem ser abordadas/consideradas (Coutinho, 2010; Viana et al., 2020).

Então, com produções científicas que têm como base as ciências humanas e sociais só contribuem com a área de educação física, ultrapassando apenas o uso das RC: 88594 
ciências da saúde, ocorre a possibilidade de colocar a educação física no mesmo patamar de relevância e importância dos outros componentes do currículo escolar (Balbino e Urt, 2018). Durante o processo de pesquisa, artigos e livros foram traduzidos para outros idiomas. Esta atitude é importante para ampliar o alcance da pesquisa, podendo a produção se relacionar tanto com literatura nacional quanto com internacional, mostrando uma capacidade de comunicação, acesso, cooperação e apoio com o que está sendo produzido pelo mundo dentro da educação física (Coutinho, 2010).

No tocante à produção científica no Norte, Pereira e Silveira (2019) realizaram uma análise da produção científica de pesquisadores da Região Norte no Encontro Nacional de Pesquisa em Educação em Ciências e relataram que o Norte tem a menor quantidade de pesquisas presentes no evento. O estudo ainda mostra que o Amapá não realizou nenhuma apresentação e trabalho nas edições de 2009, 2011,2013,2015 e 2017. De acordo com o estudo, o maior ou menor número de produções tem relação com a localidade do campus das universidades, uma vez que são responsáveis por grande parte das atividades científicas. Corroborando com o estudo citado, Sidone et al. (2016) ao fazer uma análise de produção de artigo entre os anos de 2007 -2009 das regiões Sul e Sudeste indica que estas foram responsáveis por mais de três quartos da produção total. Outras regiões como Nordeste 15\% e Centro-Oeste e Norte juntas não atingiram $10 \%$ do total nacional. Além da concentração de universidades nas regiões Sul e Sudeste, outro fator apontado para esta produção é a maior disponibilidade de recursos humanos.

\section{CONCLUSÕES}

Durante o mestrado a produção científica em várias formas se mostrou necessária durante o processo de formação. Unindo a teoria com a prática da escrita, facilitou a produção da dissertação que deve ser apresentada ao final do curso. Através do processo de organização, planejamento das ideias resultou em um novo pensamento estruturado de acordo com as normas da academia, mas que não se limita a esse espaço e normas. 
Tendo uma contribuição que vai além da escrita científica, durante esse percurso aprendizagem foi de forma ampla, ou seja, criação de aplicativo, sites, livros, artigos, metodologias de práticas pedagógicas. Toda essa experiência irá impactar de forma positiva o futuro como pesquisador e profissional de educação física.

Nesse contexto, toda a produção no decorrer do mestrado vem também contribuir tanto quantitativamente quanto qualitativamente para a produção científica da região norte, impactando de forma positiva nela e no programa de mestrado. Além da importância na contribuição da criação e divulgação científica, as produções tendem a impactar positivamente na avaliação e na manutenção do programa PROFEPTIFAP, realizadas pela CAPES.

\section{REFERÊNCIAS}

BALBINO, S. I.; URT, S. D. C. Prática Pedagógica em Educação Física para a Educação Integral em Tempo Integral. Pensar a Prática, v. 21, n. 4, p. 775-785, 2018.

CAPES. Ficha de Avaliação - Programas Acadêmicos e Profissionais Área 46: Ensino. Brasília DF, 2020. Disponível em: < https://www.gov.br/capes/pt-br/centraisde-conteudo/FICHA_ENSINO.pdf >. Acesso em: 14 Jun 2021.

COUTINHO, R. X. A influência da Produção Científica nas Práticas de Professores de Educação Física, Ciências e Matemática em Escolas Públicas Municiais de Uruguaiana - RS. 2010. 94p. (Mestrado). Universidade Federal de Santa Maria, Santa Maria RS.

FALASTER, C.; FERREIRA, M. P.; GOUVEA, D. M. R. D. O efeito da publicação científica do orientador na publicação dos seus orientados. Revista de Administração Contemporânea, v. 21, n. 4, p. 458-480, 2017.

GOOGLEANALYTICS. Google Analytics Aplaticativo Oficial EFE - Pagina Inicial.

2021.

Disponível

em: 
https://analytics.google.com/analytics/web/?authuser=1\#/p265457828/reports/default home >. Acesso em: 14 Jun 2021.

MACHADO, M. F. R. C.; URBANETZ, S. T. Mestrado profissional em educação profissional e tecnológica no Instituto Federal do Paraná: desafios e expectativas. Atos de Pesquisa em Educação, v. 14, n. 2, p. 885-903, 2019.

MAIA, R. T. A importância da disciplina de metodologia científica no desenvolvimento de produções acadêmicas de qualidade no nível superior. Revista Urutágua, v. 14, n. 1, 2008.

PEREIRA, T. Z. M.; SILVEIRA, C. A Produção Acadêmica Da Região Norte: Uma Análise Na Ata Do Xi Encontro Nacional De Pesquisa Em Educação Em Ciências. REAMEC - Rede Amazônica de Educação em Ciências e Matemática, v. 7, n. 2, p. 245-260, 2019.

PLAYCONSOLE. Google Play Console Painel - EFE EduFIsEPT. 2021. Disponível em:

https://play.google.com/console/u/0/developers/4760644030222400117/app/497210 7118591571772/app-dashboard?timespan=thirtyDays\&showKpiMenu=null >. Acesso em: 14 Jun 2021.

RMNC. Revista Multidisciplinar Nucleo do Conhecimento. São Paulo SP, 2021. Disponível em: < https://www.nucleodoconhecimento.com.br/ >. Acesso em: 14 Jun 2021.

ROSSI, A. V. Sobre A Valorização Das Contribuições Da Divulgação Científica No Brasil. In: VOIGT, C. L. (Ed.). $O$ ensino de química. Ponta Grossa PR: Atena Editora, v.1, 2019. cap. 11, p.136-148.

RSD. Research, Society and Development. Vargem Grande paulista SP, 2021. Disponível em: < https://rsdjournal.org/index.php/rsd >. Acesso em: 14 Jun 2021. 
SIDONE, O. J. G.; HADDAD, E. A.; MENA-CHALCO, J. P. A ciência nas regiões brasileiras: evolução da produção e das redes de colaboração científica. Transinformação, v. 28, n. 1, p. 15-32, 2016.

URBANETZ, S. T.; CASSIANO, E. L.; BETTONI, V. O Mestrado Profissional Em Educação Profissional E Tecnológica-Profept-E O Significado Dessa Oferta De Formação Em Pós Graduação No Brasil. Movimento-revista de educação, v. 7, n. 14, 2020.

VIANA, V. N.; DIAS, C. A. G. D. M. Educação Física e EPT - Temáticas em Educação Profissional e Tecnológica (EPT). Macapá AP: 2020. 45 p. ISBN 97865-86069-90-7. Disponível em: https://www.nucleodoconhecimento.com.br/livros/wp-content/uploads/2020/09/livroeducacao-Fisica-e-EPT-educacao-profissional-e-tecnologica-2020.pdf >.

. Physical Education and PTE - Topics in Professional and Technological Education (PTE). Macapá AP: 2020b. 45 p. ISBN 978-65-86069-89-1. Disponível em: < https://www.nucleodoconhecimento.com.br/ivros/en/education/physicaleducation-and-pte $>$.

VIANA, V. N. et al. Quadras de esportes em condições de uso adequado no Brasil: influência no ensino-aprendizagem nas aulas de Educação Física (2015). Research, Society and Development, v. 9, n. 8, p. e239985704, 2020. Disponível em: < https://rsdjournal.org/index.php/rsd/article/view/5704/4727 >.

VIANA, V. N. et al. Manuel de pratiques en éducation physique en éducation professionnelle et technologique utilisant l'application gratuite EFE - EPTFIS. Revista Científica Multidisciplinar Núcleo do Conhecimento, v. 5, p. 4, 2021d. Disponível em: < https://www.nucleodoconhecimento.com.br/education-physics-fr/manuel-depratiques $>$.

. Manuale di pratiche in educazione fisica nell'educazione professionale e tecnologica utilizzando l'applicazione gratuita EFE - EPTFIS. Revista Científica 
Multidisciplinar Núcleo do Conhecimento, v. 5, n. 4, p. 65-76, 2021e. Disponível em: < https://www.nucleodoconhecimento.com.br/educazione-fisica-it/manuale-dipratiche $>$.

Handbuch der Praktiken im Sportunterricht im beruflichen und technologischen Unterricht mit der kostenlosen Anwendung EFE - EPTFIS. Revista Científica Multidisciplinar Núcleo do Conhecimento, v. 5, n. 4, p. 6576, 2021f. Disponível em: < https://www.nucleodoconhecimento.com.br/bildungphysik-de/handbuch-der-praktiken $>$.

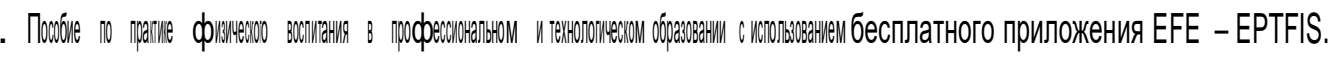

Revista Científica Multidisciplinar Núcleo do Conhecimento, v. 5, n. 4, p.65-76, $2021 \mathrm{~g}$.

Disponível em: <

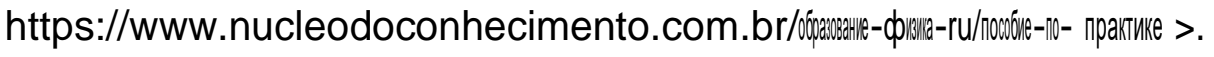

VIANA, V. N. et al. Manual De Praticas Em Educação Física Na Educação Profissional E Tecnológica Utilizando O Aplicativo Gratuito EFE - EPTFIS. Revista Científica Multidisciplinar Núcleo do Conhecimento, v. 5, n. 4, p. 65-76, 2021. Disponível em: < https://www.nucleodoconhecimento.com.br/educacao-fisica/manual-depraticas $>$.

. Manual Of Practices In Physical Education In Professional And Technological Education Using The Free Application EFE - EPTFIS. Revista Científica Multidisciplinar Núcleo do Conhecimento, v. 5, n. 4, p. 65-76, 2021b. Disponível em: < https://www.nucleodoconhecimento.com.br/education-physics-en/manual-ofpractices $>$.

- Manual De Prácticas En Educación Física En Educación Profesional Y Tecnológica Utilizando La Aplicación Gratuita EFE - EPTFIS. Revista Científica Multidisciplinar Núcleo do Conhecimento, v. 5, n. 4, p. 65-76, 2021c. Disponível 
em: < https://www.nucleodoconhecimento.com.br/educacion-fisica-es/manual-depracticas $>$.

YAMAGUCHI, K. K. D. L.; FURTADO, M. A. S. A Escrita Científica Como Aprendizagem Contextualizada: Uma Abordagem Metodológica A Partir De Um Experimento De Mistura De Cores In: VOIGT, C. L. (Ed.). O ensino de química. Ponta Grossa PR: Atena Editora, v.1, 2019. cap. 12, p.149-158.

Enviado: Junho, 2021.

Aprovado: Junho, 2021. 